\title{
Lung cancer mortality among construction workers: implications for early detection
}

\author{
John M Dement 이, ${ }^{1}$ Knut Ringen, ${ }^{2}$ Stella Hines, ${ }^{3}$ Kim Cranford, ${ }^{4}$ Patricia Quinn ${ }^{2}$
}

\begin{abstract}
- Additional material is published online only. To view please visit the journal online (http://dx.doi.org/10.1136/ oemed-2019-106196).

'Division of Occupational and Environmental Medicine, Duke University Medical Center, Durham, North Carolina, USA ${ }^{2}$ The Center for Construction Research and Training (CPWR), Silver Spring, Maryland, USA ${ }^{3}$ Division of Occupational and Environmental Medicine, School of Medicine, University of Maryland Baltimore, Baltimore, Maryland, USA

${ }^{4}$ Zenith American Solutions, Oak Ridge, Tennessee, USA
\end{abstract}

\section{Correspondence to}

Dr John M Dement, Division of Occupational and Environmental Medicine, Duke University Medical Center, Durham, NC 27705, USA;

john.dement@duke.edu

Received 11 September 2019 Revised 20 December 2019 Accepted 14 January 2020 Published Online First 29 January 2020
ABSTRACT

Objectives This study examined predictors of lung cancer mortality, beyond age and smoking, among construction workers employed at US Department of Energy (DOE) sites to better define eligibility for low-dose $\mathrm{CT}$ (LDCT) lung cancer screening.

Methods Predictive models were based on 17069 workers and 352 lung cancer deaths. Risk factors included age, gender, race/ethnicity, cigarette smoking, years of trade or DOE work, body mass index (BMI), chest $X$-ray results, spirometry results, respiratory symptoms, beryllium sensitisation and personal history of cancer. Competing risk Cox models were used to obtain HRs and to predict 5-year risks.

Results Factors beyond age and smoking included in the final predictive model were chest $X$-ray changes, abnormal lung function, chronic obstructive pulmonary disease (COPD), respiratory symptoms, BMI, personal history of cancer and having worked 5 or more years at a DOE site or in construction. Risk-based LDCT eligibility demonstrated improved sensitivity, specificity and positive predictive value compared with current US Preventive Services Task Force guidelines. The risk of lung cancer death from 5 years of work in the construction industry or at a DOE site was comparable with the risk from a personal cancer history, a family history of cancer or a diagnosis of COPD. LDCT eligibility criteria used for DOE construction workers, which includes factors beyond age and smoking, identified $86 \%$ of participants who eventually would die from lung cancer compared with $51 \%$ based on age and smoking alone.

Conclusions Results support inclusion of risk from occupational exposures and non-malignant respiratory clinical findings in LDCT clinical guidelines.

\section{INTRODUCTION}

Construction workers are occupationally exposed to a number of respiratory carcinogens including asbestos, silica, beryllium and welding fumes. Prior studies have demonstrated elevated risk of lung cancer among these workers. ${ }^{1-5}$

In 2011, the National Lung Screening Trial (NLST) demonstrated a $20 \%$ reduction in mortality attributable to three annual screenings using lowdose CT (LDCT). ${ }^{6}$ Subsequently, the US Preventive Services Task Force (USPSTF) of the US Public Health Service recommended lung cancer screening, as have other professional organisations, with some (eg, Lung Cancer Alliance) recommending that screening should only be undertaken as a structured programme in centres with considerable expertise in lung cancer care. The USPSTF

\section{Key messages}

What is already known about this subject?

- The National Lung Screening Trial demonstrated a $20 \%$ reduction in mortality attributable to three annual screenings using low-dose CT (LDCT) using eligibly criteria based on age and smoking history.

\section{What are the new findings?}

- Lung cancer risk among construction workers can be reasonably predicted based on age and smoking history as well as other risk factors including chest X-rays, spirometry, prior cancer history and duration of construction work.

\section{How might this impact on policy or clinical practice in the foreseeable future? \\ - Application of additional risk factors beyond age and smoking history including predictive risk models for LDCT eligibility has potential for better targeting of those at high risk, resulting in a higher rate of lung cancer detection at an early stage when treatment is likely to be more effective.}

currently recommends LDCT for individuals 55-80 years of age with at least 30 pack-years of smoking and, for former smokers, no more than 15 years since quitting. ${ }^{7}$

Determining eligibility for lung cancer screening has evolved. The NLST relied on age and smoking history. The most current clinical guideline by the National Comprehensive Cancer Network (NCCN) includes two risk categories: category 1 , which is limited to age (55-77 years) and smoking history (current or former smokers with $\geq 30$ packyears and if former smoker quit within 15 years), and category 2, which includes age ( $\geq 50$ years), smoking history ( $\geq 20$ pack-years) and 'additional risk factors'. 8 Additional risk factors include personal history of cancer or lung disease, family history of cancer, radon exposure and occupational exposure to carcinogens. NCCN guidelines suggest that these additional risk factors may be considered through either fixed eligibility criteria or through use of predictive statistical models.

The Building Trades National Medical Screening Program (BTMed) is an occupational medical screening programme for construction trades workers previously employed in USA nuclear weapons facilities. BTMed participants are at significantly increased risk of lung cancer. ${ }^{3-5}$ The 
current study investigated lung cancer mortality risk factors among BTMed participants included in a recent mortality update of this cohort. ${ }^{4}$ Study objectives were to develop a predictive model for lung cancer mortality incorporating occupational and non-occupational risk factors and to evaluate potential use of the model for targeting high-risk individuals for lung cancer screening.

\section{METHODS}

\section{Study cohort and risk factors}

The BTMed medical protocol has been described in prior publications $^{3-5}$ 9-15 and includes: a work history interview; a medical history and symptom questionnaire; a comprehensive physical examination; a posterior-anterior chest radiograph classified by a B-reader according to International Labour Office (ILO) Classification of Radiographs of Pneumoconiosis ${ }^{16}{ }^{17}$; audiometry; a panel of blood tests chosen to assess organ damage from identified toxins; beryllium lymphocyte proliferation test (BeLPT; a blood test for beryllium sensitisation); stool faecal immunochemical testing; and spirometry meeting American Thoracic Society (ATS) standards. ${ }^{18} 19$ In 2011, BTMed began offering LDCT screening for workers meeting eligibility requirements. ${ }^{15}$

The most recent overall mortality cohort included 24096 workers participating in BTMed between 1 January 1998 and 31 December 2016. ${ }^{4}$ The current study was restricted to 352 lung cancer deaths among 17069 workers who completed initial medical examinations with chest radiographs and spirometry and had data on other covariates considered in the statistical models. Individuals excluded were 3212 workers who only completed a work history interview and 3815 workers who lacked information on one or more lung cancer risk factors. The lung cancer risk in the study cohort was comparable with the overall mortality cohort, and the study cohort did not differ meaningfully from the mortality cohort by age, gender or race/ethnicity.

Candidate lung cancer risk factors were chosen a priori based on the published literature as well as our prior work within this population. ${ }^{489111520}$ All risk factors were assessed at cohort entry and included age, gender, race/ethnicity (white, black and all other), cigarette smoking history (status nd pack-years), years of trade or Department of Energy (DOE) work, body mass index (BMI; $\mathrm{kg} / \mathrm{m}^{2}$ ), chest X-ray category (ILO categorisation), spirometry category (normal, obstructive, restrictive and mixed), respiratory symptoms (cough, phlegm and cough with phlegm), chronic obstructive pulmonary disease (COPD), beryllium sensitisation and personal history of cancer. BTMed collects worker-reported causes of death for biological parents, and this information was used to develop a variable for 'parental cancer mortality'. Medical history questionnaires defined any personal history of cancer (yes/no).

Smoking status was classified as current, never or former smokers. Former smokers were further classified by years since last having smoked ( $<15$ years, 15-25 years and $>25$ years). Smoking intensity and duration was estimated and expressed as pack-years. Workers were dichotomised with regard to years of work in a construction trade or at a DOE facility ( $<5$ years and $\geq 5$ years), based on current BTMed LDCT eligibility. ${ }^{15}$ A chest $\mathrm{X}$-ray parenchymal abnormality was defined as a B-read profusion score of $1 / 0$ or greater for any shape or size of small opacity seen bilaterally. Some analyses further stratified parenchymal changes by B-read profusion category $(0 /--0 / 0,0 / 1,1 / 0-1 / 2$, $2 / 1-2 / 3$ and $3 / 2-3 /+) .^{5}$ A pleural abnormality was defined as bilateral pleural thickening or plaques, with or without calcification. ${ }^{21}$ Chest X-ray results were also classified into four mutually exclusive categories (normal, pleural changes only, parenchymal changes only and pleural plus parenchymal changes) for some analyses.

Predicted spirometry values were based on the US population and classified by ATS/European Respiratory Society (ERS) criteria (normal, restrictive, obstructive or mixed restrictive/ obstructive). ${ }^{22}{ }^{23} \mathrm{COPD}$ was defined as a ratio of $1 \mathrm{~s}$ force expiratory volume to forced vital capacity $\left(\mathrm{FEV}_{1} / \mathrm{FVC}\right)$ below the lower limit of normal. ${ }^{23}$

Beryllium sensitisation was defined as one abnormal plus one borderline BeLPT tests or two abnormal BeLPT tests. ${ }^{24}$ History of chronic cough and chronic phlegm production was defined as in our prior publication (cough, phlegm and cough with phlegm). ${ }^{10}$

\section{Statistical analyses}

Workers dying of lung cancer were compared with those not dying of lung cancer by demographic characteristics and risk factors described above using analysis of variance, Wilcoxon rank-sum tests or $\chi^{2}$ tests of general association as appropriate.

Cause-specific competing risk Cox models were developed to estimate lung cancer mortality HRs and 95\% CIs. To allow comparisons with other published lung cancer risk models, time since cohort entry was used as the time axis with adjustment for age at cohort entry. ${ }^{25}$

The baseline Cox model controlled for age at cohort entry, gender and race/ethnicity, and these covariates were retained in all subsequent models. Other covariates with a likelihood ratio $\mathrm{p}$ value $<0.20$ in screening models were included in the initial multivariable models. As the primary study objective was risk prediction, final models retained covariates with a Wald $\chi^{2}$ $\mathrm{p}<0.10$. Model Akaike Information Criterion (AIC) was used to evaluate covariates and facilitate model comparisons. Cox model assumptions were assessed using SAS V.9.4 model diagnostics. Functional form of continuous variables was assessed by substitution of restricted cubic splines for linear terms.

Calibration of the predictive models was evaluated graphically and globally using the Grønnesby-Borgan goodness-of-fit test. ${ }^{26}$ Model predicted discrimination was quantified using the concordance C-statistics. ${ }^{27}$ Model optimism was evaluated following procedures described by Harrell et al based on bootstrapping 200 random samples drawn with replacement from the study cohort. ${ }^{2829}$

\section{LDCT eligibility criteria evaluation}

BTMed adheres to the NCCN lung cancer guidelines for screening eligibility criteria with the addition of a requirement of 5 years of work in the construction industry or DOE site or 5 years of work in a job with exposures to asbestos, silica, beryllium, chromium, radiation or welding. ${ }^{815}$ Workers with 20 packyears of smoking and who also have COPD or pleural plaque (a marker of asbestos exposure) are eligible with fewer than 5 years of work. Screening is additionally offered to workers with chest radiograph findings consistent with asbestosis without regard to smoking history or years of construction/DOE work. ${ }^{30}$ Details of BTMed LDCT eligibility criteria are detailed in online supplementary table $\mathrm{S} 1 .^{15}$

We evaluated the sensitivity, specificity and positive predictive value (PPV) of current BTMed LDCT eligibility criteria for identifying lung cancer deaths. For comparison and reference, sensitivity, specificity and PPV of the NCCN and USPSTF eligibility

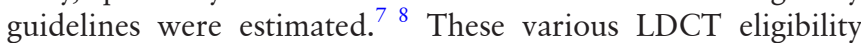
criteria were applied to cohort entry examinations and restricted 
to workers $50-80$ years of age and with a per cent predicted $\mathrm{FEV}_{1}>40 \%$. The age range 50-80 years spanned the recommended range for all LDCT criteria evaluated, and the FEV criterion was used to limit the analyses to those more likely to be candidates for intervention should a lung cancer be detected.

We also evaluated potential use of predicted risks from the best fitting statistical model to determine LDCT programme eligibility. Effects of various predicted risk thresholds for LDCT eligibility on sensitivity, specificity and PPV were evaluated. Predicted risk thresholds were based on: (1) scanning the same number of individuals eligible by current BTMed criteria (online supplementary table S1), (2) scanning the same number as the Tammemagi 2014 model (6-year risk threshold $\geq 1.3 \%)^{31}$ or (3) scanning the same number as the current USPSTF criteria.

For application of the Tammemagi model estimates, we assumed that BTMed population education level was 'some post high school education' (Tammemagi level=3) as most BTMed participants have trade apprentice training post-high school.

All statistical analyses were performed using SAS V.9.4. ${ }^{32}$

\section{RESULTS}

\section{Lung cancer risk models}

Demographic and clinical characteristics of the study population are shown in table 1, overall and stratified by lung cancer status during follow-up. Mean follow-up duration was 8.7 years ( $\mathrm{SD}=4.9$ years). Workers dying of lung cancer compared with those not dying of lung cancer during follow-up were significantly older, smoked significantly more based on smoking status and mean pack-years, had a higher prevalence of pleural changes and parenchymal changes and a higher prevalence of abnormal lung function. Lung cancer cases had a significantly higher prevalence of COPD, as well as respiratory symptoms, and personal history of cancer. Cumulative lung cancer deaths stratified by categorical risk factors in table 1 are provided in the supplemental materials.

Initial covariate screening found that smoking status, smoking pack-years, ILO chest $\mathrm{x}$-ray category, spirometry category, COPD by spirometry, respiratory symptoms, personal history of cancer, BMI category, and having worked in construction or at a DOE site for five or more years met criteria for multivariate model inclusion. Neither beryllium sensitivity nor the covariate for parental cancer mortality approached criteria for model inclusion. Substitution of restricted cubic splines for smoking pack-years, age, or BMI did not meaningfully increase model fit; therefore, less complex linear terms were retained all models.

Three Cox models were developed using different criteria for categorisation of chest X-ray and spirometry results. Detailed results for all three models are provided in the supplemental materials (online supplementary tables S3-S5). A bilateral pleural abnormality was associated with lung cancer risk in the univariate analyses and screening models but did not meet model inclusion criteria in the multivariate models and was omitted from the final multivariate models that categorised pleural changes separate from parenchymal changes. All three models demonstrated good discrimination, with C-statistics ranging from 0.874 to 0.880 . Grønnesby and Borgan goodness-of-fit tests demonstrated good overall calibration for each model, which was verified by plots of observed and predicted lung cancer risk by decile of predicted risk (online supplemental figures S1-S3). Bootstrapping to evaluate optimism in the models reduced the C-statistics from 0.010 to 0.017 .

Results of the best fitting model by AIC are shown in table 2 . In this model, spirometry was classified into four mutually
Table 1 Descriptive statistics at cohort entry

\begin{tabular}{|c|c|c|c|c|}
\hline Characteristic & $\begin{array}{l}\text { Died of lung } \\
\text { cancer } \\
(n=352)^{*}\end{array}$ & $\begin{array}{l}\text { Not dying of } \\
\text { lung cancer } \\
(n=16717)\end{array}$ & $P$ valuet & $\begin{array}{l}\text { Entire cohort } \\
(n=17069)\end{array}$ \\
\hline Age (mean, SD) & $67.2(9.90)$ & $59.9(12.27)$ & $<0.0001$ & $60.0(12.27)$ \\
\hline Male sex (N, \%) & 336 (95.5) & $15797(94.5)$ & 0.4347 & $16133(94.5)$ \\
\hline Race/ethnicity $(\mathrm{N}, \%)$ & & & 0.0729 & \\
\hline White & $315(89.4)$ & $14383(86.0)$ & & $14698(86.1)$ \\
\hline Black & $30(8.5)$ & $1618(9.7)$ & & $1648(9.7)$ \\
\hline All other & $7(2.0)$ & $716(4.3)$ & & $723(4.2)$ \\
\hline $\begin{array}{l}\text { Smoking status } \\
(\mathrm{N}, \%)\end{array}$ & & & $<0.0001$ & \\
\hline Never smoked & $7(2.0)$ & $5806(34.7)$ & & $5813(34.1)$ \\
\hline $\begin{array}{l}\text { Former smoker } \\
\text { (<15 years since } \\
\text { quit) }\end{array}$ & $93(26.4)$ & 2660 (15.9) & & $2753(16.1)$ \\
\hline $\begin{array}{l}\text { Former smoker } \\
\text { (15-25 years since } \\
\text { quit) }\end{array}$ & $48(13.6)$ & 1825 (10.9) & & $1873(11.0)$ \\
\hline $\begin{array}{l}\text { Former smoker } \\
\text { (>25 years since } \\
\text { quit) }\end{array}$ & $51(14.5)$ & 3107 (18.6) & & 3158 (18.5) \\
\hline Current smoker & $153(43.4)$ & 3319 (19.9) & & $3472(20.3)$ \\
\hline $\begin{array}{l}\text { Smoking pack-years } \\
\text { (mean, SD) }\end{array}$ & $48.0(28.89)$ & $21.1(25.57)$ & $<0.0001$ & $21.7(25.92)$ \\
\hline
\end{tabular}

CXR B-reader

category (N, \%)‡

Normal $\quad 262(74.4) \quad 14816(88.6) \quad<0.0001 \quad 15080(88.3)$

$\begin{array}{llll}\text { Pleural changes } & 67(19.1) & 2286(13.7) & 0.0039\end{array} 2353(13.8)$

Parenchymal

profusion category

$\begin{array}{llll}0 /-0 / 0 & 280(79.6) & 15881(95.0) & 16161(94.7)\end{array}$

$0 / 1 \quad 11(3.1) \quad 166(1.0) \quad 177(1.04)$

$1 / 0-1 / 2 \quad 52(14.8) \quad 591(3.5) \quad 643(3.8)$

$\begin{array}{llll}2 / 1-2 / 3 & 7(2.0) & 64(0.4) & 71(0.4)\end{array}$

$\begin{array}{llll}3 / 2-3 /+ & 2(0.6) & 15(0.1) & 17(0.1)\end{array}$

Spirometry category

$(\mathrm{N}, \%)$

\begin{tabular}{|c|c|c|c|}
\hline Normal & $107(30.4)$ & $10036(60.0)$ & $10143(59.4)$ \\
\hline Restrictive & $109(31.0)$ & $4267(25.5)$ & $4376(25.6)$ \\
\hline Obstructive & $41(11.7)$ & $1326(7.9)$ & $1367(8.0)$ \\
\hline Mixed & $95(27.0)$ & $1088(6.5)$ & $1183(6.9)$ \\
\hline OPD by spirometry & $136(38.6)$ & 2414 (14.4) & $2550(14.9)$ \\
\hline
\end{tabular}

criteria $(\mathrm{N}, \%)$

\begin{tabular}{|c|c|c|c|c|}
\hline \multicolumn{2}{|l|}{$\begin{array}{l}\text { Respiratory } \\
\text { symptoms (N, \%) }\end{array}$} & \multicolumn{3}{|c|}{$<0.0001$} \\
\hline None & $139(39.4)$ & $10273(61.5)$ & & $10412(61.0)$ \\
\hline Cough & $38(10.8)$ & $1673(10.0)$ & & $1711(10.0)$ \\
\hline Phlegm & $34(9.7)$ & $1567(9.4)$ & & $1601(9.4)$ \\
\hline $\begin{array}{l}\text { Cough and } \\
\text { phlegm }\end{array}$ & $141(40.1)$ & $3204(19.2)$ & & 3345 (19.6) \\
\hline $\begin{array}{l}\geq 5 \text { years of trade } \\
\text { work or DOE work } \\
(\mathrm{N}, \%)\end{array}$ & 321 (91.2) & $14885(89.0)$ & 0.2000 & $15206(89.1)$ \\
\hline $\begin{array}{l}\text { Beryllium sensitivity } \\
(\mathrm{N}, \%) \S\end{array}$ & $5(1.5)$ & $180(1.2)$ & 0.5794 & $185(1.2)$ \\
\hline $\begin{array}{l}\text { Body mass index } \\
\text { (BMI) (mean, SD) }\end{array}$ & $27.9(5.13)$ & $29.8(5.48)$ & $<0.0001$ & $29.7(5.48)$ \\
\hline $\begin{array}{l}\text { Personal history of } \\
\text { cancer }(\mathrm{N}, \%)\end{array}$ & $101(28.7)$ & $2838(17.0)$ & $<0.0001$ & 2939 (17.2) \\
\hline
\end{tabular}

* Per cent values are column percentage.

tP value comparing workers developing lung cancer and those not developing lung cancer. $\mp C X R$ categories are not mutually exclusive as workers can have pleural and parenchymal changes. $\$ 1110$ were missing data on beryllium sensitivity.

COPD, chronic obstructive pulmonary disease; CXR, chest X-ray.

exclusive categories (normal, restrictive, obstructive and mixed), and B-read results were classified by parenchymal profusion category. Online supplemental figure S4 provides a plot of predicted 5 -year lung cancer mortality risk at cohort entry by 


\begin{tabular}{|c|c|c|c|}
\hline Risk predictor* & HR & $95 \% \mathrm{LCL}$ & $95 \%$ UCL \\
\hline \multicolumn{4}{|l|}{ Smoking status (ref=never smoked) } \\
\hline Current & 24.32 & 10.98 & 53.85 \\
\hline Former ( $<15$ years since quit) & 16.76 & 7.54 & 37.27 \\
\hline Former (15-25 years since quit) & 10.54 & 4.70 & 23.62 \\
\hline Former ( $>25$ years since quit) & 5.90 & 2.66 & 13.09 \\
\hline Smoking pack-years (increase per pack-year) & 1.006 & 1.002 & 1.010 \\
\hline \multicolumn{4}{|l|}{ CXR B-reader category results $†$} \\
\hline \multicolumn{4}{|l|}{ Parenchymal profusion category $\ddagger(r e f=0 /-0 / 0)$} \\
\hline $0 / 1$ & 2.05 & 1.11 & 3.76 \\
\hline $1 / 0-1 / 2$ & 2.33 & 1.71 & 3.16 \\
\hline $2 / 1-2 / 3$ & 3.52 & 1.63 & 7.63 \\
\hline $3 / 2-3 /+$ & 10.55 & 2.58 & 43.20 \\
\hline \multicolumn{4}{|l|}{ Spirometry category $(r e f=$ normal)§ } \\
\hline Restrictive & 1.84 & 1.40 & 2.41 \\
\hline Obstructive & 1.38 & 0.95 & 2.00 \\
\hline Mixed & 2.98 & 2.21 & 4.01 \\
\hline \multicolumn{4}{|l|}{ Respiratory symptoms (ref=none) } \\
\hline Cough & 1.07 & 0.74 & 1.55 \\
\hline Phlegm & 1.38 & 0.95 & 2.02 \\
\hline Cough and phlegm & 1.71 & 1.34 & 2.20 \\
\hline \multicolumn{4}{|l|}{ Years of trade work or DOE work $(r e f=<5) \uparrow$} \\
\hline $5+$ & 1.56 & 1.07 & 2.26 \\
\hline Body mass index (BMI) (change per BMI unit) & 0.972 & 0.951 & 0.994 \\
\hline \multicolumn{4}{|l|}{ Personal history of cancer (ref=no) } \\
\hline Yes & 1.44 & 1.13 & 1.83 \\
\hline \multicolumn{4}{|l|}{ Model diagnostics } \\
\hline AIC & 5749.95 & & \\
\hline Model C-statistic & 0.880 & & \\
\hline Optimism corrected C-statistic & 0.868 & & \\
\hline Grønnesby and Borgan test $\mathrm{p}$ value & 0.4174 & & \\
\hline \multicolumn{4}{|c|}{ 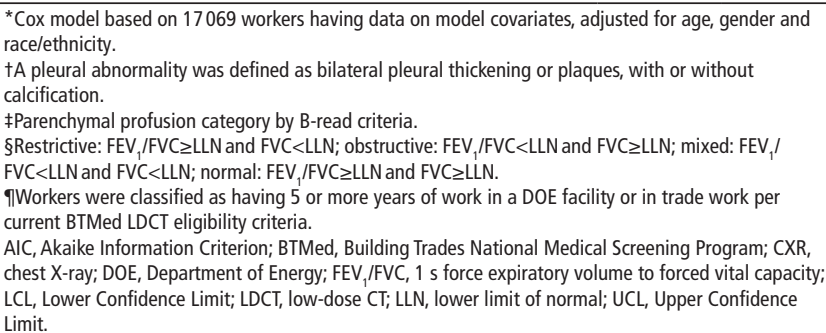 } \\
\hline
\end{tabular}

lung cancer outcome for this model. This plot is right-truncated as the distributions are highly skewed, with some individuals at very high predicted risk.

Current smokers were at very high risk for lung cancer $(\mathrm{HR}=24.32,95 \% \mathrm{CI} 10.98$ to 53.85$)$. While risk decreased with time since stopping smoking, workers who had quit for more than 25 years remained at significant risk $(\mathrm{HR}=5.90,95 \% \mathrm{CI}$ 2.66 to 13.09). Each additional pack-year of cigarette smoking increased risk even after model adjustment for smoking status $(\mathrm{HR}=1.006,95 \% \mathrm{CI} 1.002$ to 1.010$)$. Lung cancer risk increased progressively based on ILO parenchymal profusion scores. Notably, workers with a profusion score of $0 / 1$, which is below a threshold for a positive finding in many studies, were at significantly increased risk ( $\mathrm{HR}=2.05,95 \%$ CI 1.11 to 3.76$)$. Spirometry category was a significant predictor of risk with highest risk among workers with mixed restrictive/obstructive defects $(\mathrm{HR}=2.98,95 \%$ CI 2.21 to 4.01$)$. Reported respiratory symptoms increased risk, especially for those with chronic cough and phlegm production ( $\mathrm{HR}=1.71,95 \% \mathrm{CI} 1.34$ to 2.20 ). Workers with $\geq 5$ years of construction/DOE work were at significantly increased risk ( $\mathrm{HR}=1.56,95 \% \mathrm{CI} 1.07$ to 2.26$)$ and a personal
Table 3 Fixed parameter LDCT eligibility criteria comparison ${ }^{1}$

\begin{tabular}{llll}
\hline Measure & $\begin{array}{l}\text { Current BTMed } \\
\text { criteria* }\end{array}$ & $\begin{array}{l}\text { NCCN category } \\
1 \text { criteriat }\end{array}$ & USPSTF criteriał \\
\hline $\begin{array}{l}\text { Proportion 50-80 years } \\
\text { of age LDCT eligible (\%) }\end{array}$ & 44.1 & 18.7 & 19.5 \\
$\begin{array}{l}\text { Sensitivity, \% } \\
(95 \% \mathrm{Cl})\end{array}$ & 85.6 & 48.3 & 50.9 \\
$\begin{array}{l}\text { Specificity, \% } \\
(95 \% \mathrm{Cl})\end{array}$ & 56.9 to 89.6$)$ & $(42.3$ to 54.5$)$ & $(44.8$ to 57.0$)$ \\
Positive predictive value, & $(55.9$ to 57.7$)$ & 81.9 & 81.2 \\
$\%(95 \% \mathrm{Cl})$ & $(3.7$ to 4.8$)$ & 5.6 to 82.6$)$ & $(80.5$ to 81.9$)$ \\
\hline
\end{tabular}

*Results based on the mortality cohort restricted to 12508 workers $50-80$ years of age at cohort entry and having an $\mathrm{FEV}_{1}>40 \%$ predicted.

†NCCN category 1: adults aged $55-77$ years who have a $30^{+}$pack-year smoking history and currently smoke or have quit within the past 15 years.

fUSPSTF recommends annual screening for lung cancer in adults aged 55-80 years who have a 30 pack-year smoking history and currently smoke or have quit within the past 15 years.

BTMed, Building Trades National Medical Screening Program; FEV $1,1 \mathrm{~s}$ force expiratory volume; LDCT, low-dose CT; NCCN, National Comprehensive Cancer Network; USPSTF, US Preventive Services Task Force.

history of cancer significantly increased risk $(\mathrm{HR}=1.44,95 \% \mathrm{CI}$ 1.13 to 1.83 ). Similar to other studies, increased BMI was associated with reduced lung cancer risk.

\section{LDCT eligibility evaluation}

Table 3 provides a comparison of sensitivity, specificity and PPV for various fixed LDCT eligibility criteria. The current BTMed eligibility criteria had a sensitivity of $85.6 \%$, specificity of $56.8 \%$ and a PPV of $4.2 \%$. Current BTMed criteria had a substantially higher sensitivity than NCCN category $1(48.3 \%)$ or USPSTF $(50.9 \%)$ but lower specificity and PPV. Lower specificity and PPV were expected for BTMed criteria as both NCCN category 1 and USPSTF criteria are based on scanning only those at highest risk based on age and smoking.

Evaluation of risk thresholds from the BTMed model for establishing LDCT eligibility is shown in table 4. A threshold of $0.50 \%$ for the 5 -year mortality risk would result in scanning the same number of individuals as current BTMed criteria but had a higher sensitivity than current BTMed criteria $(90.0 \%$ vs $85.6 \%)$, comparable specificity ( $56.9 \%$ vs $56.8 \%$ ) and slightly higher PPV (4.4\% vs 4.2\%). A risk threshold of $0.86 \%$ would scan the same number of individuals as the Tammemagi model (with a 1.3\% 6-year risk threshold) and resulted in a sensitivity of $76.0 \%$, specificity $70.9 \%$, and PPV of $5.5 \%$. Lastly, a BTMed model risk threshold of $1.39 \%$ would scan the same number of individuals as current USPSTF criteria and performed much better than USPSTF criteria based on sensitivity $(63.5 \%$ vs $50.9 \%)$ and PPV (7.1\% vs 5.7\%), while being comparable for specificity $(81.5 \%$ vs $81.2 \%)$.

Table 5 provides a summary of model-based LDCT eligibility criteria applied to this cohort. The BTMed model at a 5-year risk threshold of $0.86 \%$ or the Tammemagi model with a 6 -year risk threshold of $1.3 \%$ resulted in scanning $30.1 \%$ of workers and both models demonstrated sensitivities much higher than USPSTF or NCCN category 1 (table 4). The BTMed model includes more occupational risk factors and is better calibrated to the BTMed population compared with the Tammemagi model with resulting higher sensitivity ( $76.0 \%$ vs $70.5 \%)$, comparable specificity $(70.9 \%$ vs $70.8 \%)$ and slightly higher PPV $(5.5 \%$ vs 5.1\%). Applying NCCN fixed criteria for category 1 and 2 risks in combination with the BTMed model or the Tammemagi model for selection of NCCN category 2 individuals resulted 
Table 4 BTMed model risk thresholds and LDCT eligibility

\begin{tabular}{|c|c|c|c|c|}
\hline $\begin{array}{l}\text { BTMED model threshold } \\
\text { criteria }\end{array}$ & $\begin{array}{l}\text { Risk threshold for LDCT } \\
\text { eligibility }(\%)^{*}\end{array}$ & Sensitivity $\%(95 \% \mathrm{Cl})$ & Specificity \% $(95 \% \mathrm{Cl})$ & $\begin{array}{l}\text { PPV \% } \\
(95 \% \mathrm{Cl})\end{array}$ \\
\hline $\begin{array}{l}\text { Same number LDCT eligible as } \\
\text { current BTMed criteria (table 1) }\end{array}$ & $\geq 0.50$ & $\begin{array}{l}90.0 \\
(85.8 \text { to } 93.3)\end{array}$ & $\begin{array}{l}56.9 \\
(56.0 \text { to } 57.8)\end{array}$ & $\begin{array}{l}4.4 \\
(3.9 \text { to } 5.0)\end{array}$ \\
\hline $\begin{array}{l}\text { Same number eligible as } \\
\text { Tammemagi model with 6-year } \\
\text { risk } \geq 1.3 \%\end{array}$ & $\geq 0.86$ & $\begin{array}{l}76.0 \\
(70.5 \text { to } 81.0)\end{array}$ & $\begin{array}{l}70.9 \\
(70.1 \text { to } 71.7)\end{array}$ & $\begin{array}{l}5.5 \\
\text { (4.8 to } 6.3 \text { ) }\end{array}$ \\
\hline $\begin{array}{l}\text { Same number eligible as USPSTF } \\
\text { criteria in this populationt }\end{array}$ & $\geq 1.39$ & $\begin{array}{l}63.5 \\
(57.4 \text { to } 69.2)\end{array}$ & $\begin{array}{l}81.5 \\
\text { (80.8 to } 82.1)\end{array}$ & $\begin{array}{l}7.1 \\
\text { (6.1 to } 8.1)\end{array}$ \\
\hline
\end{tabular}

* Model 5-year predicted risk of lung cancer mortality for individuals $50-80$ years of age and with $\mathrm{FEV}_{1} \geq 40 \%$ predicted.

tUSPSTF recommends annual screening for lung cancer in adults aged 55-80 years who have a 30 pack-year smoking history and currently smoke or have quit within the past 15 years.

BTMed, Building Trades National Medical Screening Program; FEV $_{1}$, 1s force expiratory volume; LDCT, low-dose CT; PPV, positive predictive value; USPSTF, US Preventive Services Task Force.

in improved sensitivity but slightly lower PPV compared with use of the model predicted risks alone for LDCT eligibility determination.

\section{DISCUSSION AND CONCLUSIONS}

\section{Validation of more nuanced risk profiling}

This study relied on mortality data instead of incidence data to identify risk factors. This is appropriate for lung cancer since incidence and mortality are closely aligned due to poor survival. The BTMed LDCT programme started in 2011, and 1290 workers had participated in the programme with 20 non-small cell lung cancers detected at stages 1 or 2 through September 2016. We do not believe the level of LDCT participation and lung cancer detection impacted our results in a meaningful way.

We confirmed an excess risk of lung cancer among workers with a profusion score $\geq 1 / 0$ and provided strong evidence for excess lung cancer risk among workers with parenchymal profusion scores $<1 / 0$. $^{3}$ Pleural abnormalities were associated with increased lung cancer risk in the univariate analyses and in the baseline models but not in the multivariate models. Pleural changes are considered a marker of asbestos exposure; however, inclusion of other covariates such as parenchymal changes, lung function abnormalities and DOE/construction work duration in the models dampens the effects of pleural changes as these effects are not entirely independent. For example, 3.5\% of workers with bilateral pleural changes also had a profusion score of $0 / 1$ compared with only $0.6 \%$ of workers without pleural changes and $33.3 \%$ of workers with pleural changes also had a restrictive finding on spirometry compared with only $24.4 \%$ of workers without pleural changes.

This study demonstrated that the risk of lung cancer extends well past 15 years since cessation of smoking. ${ }^{31}$ Consistent with other studies, workers with COPD were found to be at increased lung cancer risk. ${ }^{33} 34$ Our definition of COPD was based on spirometry rather than self-report; nonetheless, HRs were remarkably similar across studies, ranging from 1.3 to 2.4. This study found workers with a restrictive defect were at increased risk. Although spirometry can suggest the presence of a restrictive process such asbestosis or silicosis, true restriction must be confirmed by lung volume measurement. Whether restriction independently predicts lung cancer or serves as a marker for exposure to known occupational carcinogens such as asbestos or silica requires further clarification. A restrictive pattern may also be associated with increased BMI; however, our models adjusted for BMI.

Other studies have found that a family history of cancer is associated with increased lung cancer risk. Our covariate for parental cancer mortality was associated with approximately a $6 \%$ increased risk in initial screening models but did not approach statistical criteria established for model inclusion. Data from the BTMed medical history is limited to reported cancer death for one or more parents rather than a complete family cancer history. Respiratory symptoms of cough and phlegm increased the lung cancer risk. Elevated BMI decreased risk, consistent with other published data, especially among smokers. ${ }^{35}$

Table 5 Model-based LDCT eligibility criteria comparison ${ }^{1}$

\begin{tabular}{|c|c|c|c|c|}
\hline Measure & $\begin{array}{l}\text { BTMed risk model calibrated } \\
\text { to Tammemagi modelt }\end{array}$ & $\begin{array}{l}\text { NCCN category } 1 \text { or category } 2 \\
\text { by BTMed predicted risk } \neq\end{array}$ & $\begin{array}{l}\text { Tammemagi } \\
\text { model§ }\end{array}$ & $\begin{array}{l}\text { NCCN category } 1 \text { or category } 2 \text { by } \\
\text { Tammemagi predicted risk } \|\end{array}$ \\
\hline $\begin{array}{l}\text { Proportion } 50-80 \text { years of age LDCT eligible } \\
(\%)\end{array}$ & 30.1 & 29.5 & 30.1 & 31.4 \\
\hline Sensitivity \% $(95 \% \mathrm{Cl})$ & $\begin{array}{l}76.0 \\
(70.1 \text { to } 81.0)\end{array}$ & $\begin{array}{l}72.7 \\
(70.0 \text { to } 77.9)\end{array}$ & $\begin{array}{l}70.5 \\
(64.7 \text { to } 75.8)\end{array}$ & $\begin{array}{l}71.6 \\
(65.8 \text { to } 76.9)\end{array}$ \\
\hline Specificity \% (95\% Cl) & $\begin{array}{l}70.9 \\
(70.1 \text { to } 71.7)\end{array}$ & $\begin{array}{l}71.5 \\
(70.7 \text { to } 72.3)\end{array}$ & $\begin{array}{l}70.8 \\
(70.0 \text { to } 71.6)\end{array}$ & $\begin{array}{l}69.5 \\
(68.7 \text { to } 70.4)\end{array}$ \\
\hline Positive predictive value $\%(95 \% \mathrm{Cl})$ & $\begin{array}{l}5.5 \\
(4.8 \text { to } 6.3)\end{array}$ & $\begin{array}{l}5.3 \\
(4.6 \text { to } 6.1)\end{array}$ & $\begin{array}{l}5.1 \\
(4.4 \text { to } 5.8)\end{array}$ & $\begin{array}{l}5.0 \\
(4.3 \text { to } 5.7)\end{array}$ \\
\hline
\end{tabular}

* Results based on the mortality cohort restricted to 12508 workers $50-80$ years of age at cohort entry and having an FEV $>40 \%$ predicted.

†Predicted risk threshold for BTMed mortality risk that results in screening the same number of workers as the Tammemagi 2014 model applied to this cohort, with a risk threshold $\geq 1.3 \%$. The comparable threshold for the 5 -year risk of lung cancer mortality using the BTMed model was $\geq 0.86 \%$.

$\ddagger$ NCCN category 1 or category 2 with BTMed mortality risk $\geq 0.86 \%$. Category 2 would be considered NCCN category $2 a^{8}$

§Tammemagi ${ }^{31}$ predicted 6-year lung cancer risk $\geq 1.3 \%$, which results in the same number CT eligible as the USPSTF criteria in the PLCO cohort.

INCCN category 1 or category 2 with Tammemagi ${ }^{31}$ predicted 6 -year lung cancer risk $\geq 1.3 \%$. Category 2 would be considered NCCN category $2 a^{8}{ }^{8}$

BTMed, Building Trades National Medical Screening Program; FEV 1 , 1s force expiratory volume; LDCT, low-dose CT; NCCN, National Comprehensive Cancer Network; PLCO,

Prostate, Colorectal, and Ovarian Cancer Screening Trial; USPSTF, US Preventive Services Task Force. 
The BTMed risk model incorporates occupation, defined as 5 years of work in the construction industry or at a DOE site, as well as chest X-ray and pulmonary function covariates, which serve as indicators of occupational exposures to carcinogens (eg, asbestos and silica). Our model found that the risk from 5 years of work in the construction industry or at a DOE site is comparable with the risk from a personal cancer history, a family history of cancer or a diagnosis of COPD seen in other studies. ${ }^{36}$

\section{Implications for clinical guideline recommendations}

Better prediction of lung cancer risk should facilitate better targeting of high-risk individuals for LDCT screening. USPSTF and NCCN category 1 guidelines target high-risk individuals based on smoking and age. Application of either criterion to the BTMed cohort resulted in sensitivities of only approximately $48 \%-51 \%$, which means that nearly half of workers who would eventually die from lung cancer would not be offered LDCT participation at cohort entry. NCCN category 2 eligibility extends participation to many additional high-risk individuals through use of different age and smoking criteria as well incorporation of additional risk factors, including occupational exposure to carcinogens. Current BTMed LDCT programme eligibility incorporate NCCN category 2 guidelines through fixed eligibility criteria based on work in construction or at a DOE facility as well as clinical data demonstrating lung disease. In this study application of current BTMed criteria resulted in substantially increased sensitivity compared with USPSTF or NCCN category 1, identifying approximately $86 \%$ of those who would subsequently die of lung cancer during follow-up.

Consistent with other studies, we found that application of predictive risk models, either directly or as a supplement to other risk factor criteria such as NCCN category 2, has potential to improve LDCT yield and screening efficiency compared with USPSTF criteria. ${ }^{8}$ Application of the BTMed or the Tammemagi models in the context of NCCN category 2 eligibility resulted in greatly improved sensitivity compared with USPSTF criteria $(72.7 \%$ and $71.6 \%$ vs $50.9 \%)$ while maintaining good specificity (71.5\% and 69.5\%) and PPV (5.3\% and 5.0\%). While the BTMed risk model is preferred for this specific cohort, the Tammemagi risk calculator with a 6-year risk threshold of $\geq 1.3 \%$ performs well and can be used for NCCN category 2 eligibility where fewer occupational risk factors are known. Incorporation of risks beyond age and smoking into eligibility criteria for LDCT lung cancer screening has potential to save many additional lives.

\section{Strengths, limitations and future directions}

Strengths of this study include a large cohort with a high risk of lung cancer, good occupational and medical histories, as well as lung function and chest X-ray data. We know of no similar cohort of workers in existence in the USA.

There are also some weaknesses. First, 29.6\% of overall mortality study participants were excluded due to some missing data, and we did not attempt to impute these values. However, the lung cancer mortality experience and demographic characteristics of the study population were comparable with the overall mortality cohort. Second, the USPSTF recommends that screening be discontinued if a person develops a health problem limiting life expectancy or the ability/willingness to have curative lung surgery. We did not have longitudinal data sufficient to make such exclusions; therefore, some individuals identified as LDCT eligible on cohort entry might be excluded during follow-up. However, such exclusion would apply equally to all LDCT eligibility criteria evaluated, so comparisons should remain valid. Lastly, while the predictive model performed well in this cohort, external validation is needed.

Acknowledgements Dr Laura Welch, who retired as Building Trades National Medical Screening Program's medical director in 2017 after 20 years, contributed greatly to the earlier versions of the work reported here. This study could not have been conducted without the support of Zenith-American Solution staff, Anna Chen and Scott Haas in particular. We would like to thank Drs Melissa McDiarmid and Marianne Cloeren from the Division of Occupational \& Environmental Medicine University of Maryland School of Medicine for providing many valuable suggestions. We have received guidance and support from various Building and Construction Trades Council including the Central Washington, Colorado, Augusta, Knoxville, Greater Cincinnati and Idaho Councils. We received assistance from numerous people across the Department of Energy (DOE) complex including Dr Patricia Worthington, Gregory Lewis, Mary Fields and Lokie Harmond. We would like to thank them for their continued support and guidance. A special thank you to Dr Jim Morris (chair) and Lindsay Motz (administrator) from the US DOE Central Institutional Review Board (IRB) for their guidance throughout this project.

Contributors All authors participated in the collection and quality control of all data used for this study. JMD, SH and KR cogenerated study hypothesis and study analytical design. JMD conducted the statistical analyses. JMD, KR, SH and PQ developed and edited the manuscript.

Funding Funding for this work is provided by the US DOE through cooperative agreement number DE-FC01-06EH06004.

Competing interests None declared.

Patient consent for publication Not required.

Ethics approval The Central DOE Institutional Review Board approved this project (approval numbers DOE000409 and DOE000286).

Provenance and peer review Not commissioned; externally peer reviewed.

Data availability statement No data are available. Data are not available for sharing per IRB requirements.

\section{ORCID iD}

John M Dement http://orcid.org/0000-0001-8106-6017

\section{REFERENCES}

1 Dong WEI, Vaughan P, Sullivan K, et al. Mortality study of construction workers in the UK. Int J Epidemiol 1995;24:750-7.

2 Robinson C, Stern F, Halperin W, et al. Assessment of mortality in the construction industry in the United States, 1984-1986. Am J Ind Med 1995;28:49-70.

3 Dement JM, Ringen K, Welch LS, et al. Mortality of older construction and craft workers employed at department of energy (Doe) nuclear sites. Am J Ind Med 2009;52:671-82

4 Ringen K, Dement J, Cloeren M, et al. Mortality of older construction and craft workers employed at department of energy (Doe) nuclear sites: follow-up through 2016. Am J Ind Med 2019.

5 Ringen K, Dement J, Welch L, et al. Mortality of older construction and craft workers employed at department of energy (Doe) nuclear sites: follow-up through 2011. Am J Ind Med 2015;58:152-67.

6 Aberle DR, Adams AM, et al, National Lung Screening Trial Research T. Reduced lung-cancer mortality with low-dose computed tomographic screening. N Engl J Med 2011;365:395-409.

7 Moyer VA, Force U. Screening for lung cancer: U.S. preventive services Task force recommendation statement. Ann Intern Med 2014;160:330-338-8.

8 National Comprehensive Cancer Network. NCCN guidelines version 1.2020. Lung Cancer Screening National Clinical Guidelines on Oncology 2019.

9 Dement J, Welch L, Ringen $\mathrm{K}$, et al. A case-control study of airways obstruction among construction workers. Am J Ind Med 2015;58:1083-97.

10 Dement JM, Welch L, Bingham E, et al. Surveillance of respiratory diseases among construction and trade workers at department of energy nuclear sites. Am J Ind Med 2003;43:559-73

11 Dement JM, Welch L, Ringen K, et al. Airways obstruction among older construction and trade workers at department of energy nuclear sites. Am J Ind Med 2010;53:224-40.

12 Dement JM, Welch LS, Ringen K, et al. Longitudinal decline in lung function among older construction workers. Occup Environ Med 2017;74:701-8.

13 Welch L, Ringen K, Bingham E, et al. Screening for beryllium disease among construction trade workers at department of energy nuclear sites. Am J Ind Med 2004;46:207-18.

14 Welch LS, Dement J, Ringen K, et al. Impact of secondary prevention in an occupational high-risk group. J Occupatio Environment Med 2017;59:67-73.

15 Welch LS, Dement JM, Cranford K, et al. Early detection of lung cancer in a population at high risk due to occupation and smoking. Occup Environ Med 2019;76:137-42. 
16 ILO. Guidelines for the use of the ILO International classification of radiographs of pneumoconiosis, 2000 edition. Geneva: International Labour Office, 2002.

17 ILO. Guidelines for the use of the ILO International classification of radiographs of pneumoconiosis, 1980 edition. Geneva: International Labour Office, 1980.

18 ATS. Standardization of spirometry, 1994 update. Am J Respir Crit Care Med 1995;152:1107-36.

19 ATS/ERS. . ATS/ERS Task force: standardisation of lung function testing. Eur Respir J 2005:26:319-38.

20 Schubauer-Berigan MK, Couch JR, Petersen MR, et al. Cohort mortality study of workers at seven beryllium processing plants: update and associations with cumulative and maximum exposure. Occup Environ Med 2011;68:345-53.

21 Cullen MRet al. Predictors of Lung Cancer among Asbestos-exposed Men in the -Carotene and Retinol Efficacy Trial. Am J Epidemiol 2005;161:260-70.

22 Pellegrino R, Viegi G, Brusasco V, et al. Interpretative strategies for lung function tests. Eur Respir J 2005;26:948-68.

23 Hankinson JL, Odencrantz JR, Fedan KB. Spirometric reference values from a sample of the general U.S. population. Am I Respir Crit Care Med 1999;159:179-87.

24 Welch LS, Ringen K, Dement J, et al. Beryllium disease among construction trade workers at department of energy nuclear sites. Am J Ind Med 2013;56:1125-36.

25 Pencina MJ, Larson MG, D'Agostino RB. Choice of time scale and its effect on significance of predictors in longitudinal studies. Stat Med 2007;26:1343-59.

26 May S, Hosmer DW. A simplified method of calculating an overall goodness-of-fit test for the COX proportional hazards model. Lifetime Data Anal 1998;4:109-20.
27 Kremers W. SURVCSTD-Calculates the c-statistic (concordance, discrimination index) for survived data with time dependant covariates and corresponding SE and 100(1-a/pha)\% Cl. Mayo Clinic, Division of Biomedical Statistics and Informatics, 2018.

28 Harrell FE, Lee KL, Mark DB. Multivariable prognostic models: issues in developing models, evaluating assumptions and adequacy, and measuring and reducing errors. Stat Med 1996;15:361-87.

29 Miao Y, Cenzer IS, Kirby K, et al. Estimating Harrell's optimism on predictive indices using bootstrap samples. Proceedings of the SAS Global Forum 2013;13.

30 Markowitz S. Asbestos-Related lung cancer and malignant mesothelioma of the pleura: selected current issues. Semin Respir Crit Care Med 2015;36:334-46.

31 Tammemägi MC, Church TR, Hocking WG, et al. Evaluation of the lung cancer risks at which to screen ever- and never-smokers: screening rules applied to the PLCO and NLST cohorts. PLoS Med 2014;11:e1001764.10.1371/journal.pmed. 1001764

32 SAS. SAS/STAT® 9.4 User's Guide, Cary. NC: SAS Institute Inc, 2016.

33 Tammemagi CM, Pinsky PF, Caporaso NE, et al. Lung cancer risk prediction: prostate, lung, colorectal and ovarian cancer screening trial models and validation. J Nat Cancer Inst 2011;103:1058-68.

34 Marcus MW, Chen Y, Raji OY, et al. LLPi: Liverpool lung project risk prediction model for lung cancer incidence. Cancer Prevention Research 2015;8:570-5.

35 Kabat GC, Miller AB, Rohan TE. Body mass index and lung cancer risk in women. Epidemiology 2007;18:607-12.

36 Tammemägi MC, Katki HA, Hocking WG, et al. Selection criteria for lung-cancer screening. N Engl J Med 2013;368:728-36. 